\title{
APROVEITAMENTO DO RESÍDUO DE CAMARÃO
}

\author{
KARLA SUZANNE FLORENTINO DA SILVA CHAVES DAMASCENO* \\ SAMARAALVACHIAN CARDOSO ANDRADE** \\ TÂNIALÚCIAMONTENEGRO STAMFORD ***
}

\begin{abstract}
O presente trabalho de revisão de literatura teve como objetivo fornecer informações sobre a importância do aproveitamento dos resíduos do beneficiamento do camarão. Foram abordados os componentes estruturais do camarão e suas características químicas, a evolução da carcinicultura e sua relação com o meio ambiente e o aproveitamento dos resíduos do beneficiamento. O estudo evidenciou o grande potencial nutricional que os resíduos do beneficiamento do camarão apresentam, sendo necessárias pesquisas com o objetivo de viabilizar o seu aproveitamento para a alimentação humana.
\end{abstract}

* Doutora em Nutrição, Professora, Departamento de Nutrição, Universidade Federal do Rio Grande do Norte (UFRN), Natal, RN (e-mail: karlasuzanne@ufrnet.br).

** Doutora em Nutrição, Professora, Departamento de Engenharia Química, Universidade Federal de Pernambuco (UFPE), Recife, PE (e-mail: samaraandrade@uol.com.br).

*** Doutora em Nutrição, Professora, Departamento de Nutrição, UFPE, Recife, PE (e-mail: tlmstamford@yahoo.com.br). 


\section{INTRODUÇÃO}

A carcinicultura, criação de camarões em viveiro, tem apresentado crescimento significativo nos países subtropicais e tropicais em desenvolvimento, sendo praticada em mais de 50 países (CASTRO, CAVALCANTI-MATA e DUARTE, 2004). Além de representar importante alternativa para o atendimento da crescente demanda mundial por camarões, a carcinicultura vem favorecendo as regiões que desenvolvem essa importante atividade socioeconômica (CARCINICULTURA, 2005).

Dentre as aproximadamente 2.500 espécies conhecidas de camarão marinho (PÉREZ-FARFANTE, 1988 apud CARVALHO, 2005), o Penaeus monodon (no oriente) e o Litopenaeus vannamei (no ocidente) predominam no mercado internacional com cerca de $70 \%$ do volume ofertado (COELHO, 2005).

O Litopenaeus vannamei, nativo da costa sul-americana do Pacífico que se estende do Peru ao México, é comum na faixa costeira do Equador. Por apresentar taxa de crescimento uniforme e fácil adaptabilidade a diferentes condições do meio ambiente, o Litopenaeus vannamei tem sido cultivado em todos os países produtores do mundo ocidental (NANNI, 2004; COELHO, 2005). Devido à sua coloração típica e carne de boa qualidade apresenta excelente aceitação nos mercados internacionais (SCHOBER, 2002).

O oriente é responsável pela maior parte da produção mundial de camarões cultivados (CARCINICULTURA BRASILEIRA..., 2004), sendo a China, a Tailândia, o Vietnã, a Indonésia, a Índia, Bangladesh e a Malásia os mais importantes produtores (FAÇANHA, PINHEIRO e ABREU, 2001).

No ocidente, a produção em 2003 atingiu 271.000 t (cerca de 16,6\% do total mundial). Fechando o ano de 2003 com produção de 90.190 t, o que corresponde a mais de $6 \%$ da oferta mundial, o Brasil superou o Equador e o México, que tradicionalmente ocupavam o primeiro e o segundo lugares. $O$ Brasil consolidou a sua posição de líder desse hemisfério como o sexto maior produtor de camarões cultivados no mundo (CARCINICULTURA BRASILEIRA..., 2004; ORMOND et al., 2004) e mostra condições para crescimento contínuo (VASCONCELOS e SILVEIRA, 2004).

De acordo com VILLEN (2001), o processamento industrial tem como objetivo principal a transformação da matéria-prima em produto aceitável comercialmente. Em contrapartida, são gerados outros materiais de origem não intencional que apresentam papel significante na contaminação ambiental, principalmente devido a dois fatores de extrema importância: o acúmulo de matérias-primas e insumos, que envolve sérios riscos de contaminação por transporte e disposição inadequada; e a ineficiência dos processos de conversão, o que necessariamente implica na geração de resíduos (FREIRE et al., 2000).

O aproveitamento de resíduos de pescados diminui o risco de poluição ambiental e pode contribuir para o aumento do consumo de proteína animal, além de fornecer matéria-prima de baixo custo. Diversas tecnologias têm surgido para possibilitar a utilização dos resíduos como fonte alimentar de boa aceitabilidade (STEVANATO, 2006). A recuperação e a modificação desses resíduos pelas indústrias alimentícias assumem grande importância, pois permitem diminuir o custo dos insumos principais e minimizar os problemas de poluição ambiental. Porém, a transformação de material em subproduto requer longo processo baseado em tecnologias, conhecimentos, necessidades, fatores econômicos e legislação.

Esta revisão apresenta informações sobre a importância do aproveitamento dos resíduos gerados nas indústrias de beneficiamento do camarão, incentivando sua utilização como matériaprima na formulação de produtos alimentícios.

\section{EVOLUÇÃO DA CARCINICULTURA}

O cultivo do camarão marinho teve sua origem histórica no sudoeste da Ásia, quando pescadores artesanais construíam diques de terra nas zonas costeiras para o aprisionamento de pós-larvas selvagens que cresciam em condições naturais (SOUZA FILHO et al., 2003).

Os primeiros experimentos com o camarão cultivado no Brasil datam da década de 70. Nessa 
época, o governo do Rio Grande do Norte (RN) criou o "Projeto Camarão" para estudar a viabilidade do cultivo desse crustáceo devido ao declínio da extração do sal, atividade tradicional do Estado (NUNES, 2001).

No Estado de Santa Catarina (SC) também foram desenvolvidas pesquisas de reprodução, larvicultura e engorda do camarão cultivado, que resultaram na produção das primeiras pós-larvas em laboratórios (CARCINICULTURA, 2005).

O primeiro esforço organizado e orientado para a produção comercial do camarão confinado ocorreu no período de 1978/1984 por iniciativa do governo do RN, com a introdução da espécie exótica Penaeus japonicus. Essa ação reforçou o "Projeto Camarão" e envolveu a Empresa de Pesquisa Agropecuária do RN (EMPARN) para sistematizar e desenvolver os trabalhos de adaptação da espécie exótica às condições locais (SILVA, 2004; CARCINICULTURA, 2005; RABELO e NUNES, 2006). Em meados da década de 80 surgiram várias dificuldades ambientais (seca, chuvas intensas, variações de salinidade das águas) para assegurar o desenvolvimento do Penaeus japonicus no ambiente tropical brasileiro, levando à inviabilidade da carcinicultura com essa espécie. Em seguida, foram domesticadas as espécies nativas Litopenaeus subtilis, Litopenaeus paulensis e Litopenaeus schimitti. O projeto durou apenas 10 anos por não alcançar os resultados desejados, devido à baixa produtividade e pouca lucratividade (RABELO e NUNES, 2006).

No final dos anos 80 e início dos anos 90, técnicos e produtores importaram a espécie Litopenaeus vannamei, também conhecida como camarão branco do Pacífico. Seu cultivo foi bem-sucedido no Rio Grande do Norte, comprovando a afirmação de SILVA (2004) que esse tipo de camarão se adapta às mais diversas condições. A espécie havia sido cultivada com êxito no Equador e no Panamá, demonstrando adaptação aos ecossistemas do hemisfério ocidental (CARCINICULTURA, 2005).

O Estado de Santa Catarina iniciou em 1998 a criação do camarão branco-do-pacífico (Litopenaeus vannamei), cujos resultados atenderam às expectativas dos técnicos da Universidade Federal de Santa Catarina (UFSC) e dos produtores locais (LENOCH et al., 2003; BELTRAME, 2003). As pesquisas desenvolvidas comprovaram a viabilidade comercial da produção do $L$.vannamei, que se tornou a espécie mais cultivada no Brasil (CARCINICULTURA, 2005).

Segundo estatísticas, publicadas pela ONU/FAO, a expansão de 117 milhões para 130 milhões de toneladas na oferta internacional de pescado entre 1995 e 2001 foi promovida pelo incremento de 13,5 milhões de toneladas na aquicultura (ORMOND et al., 2004). De acordo com GRANDI (2004), a carcinicultura tem confirmado contínuo crescimento e boa rentabilidade, atraindo os investidores.

A carcinicultura vem ratificando avanços significativos no cenário nacional em números de produção, incrementos em área de cultivo e de produtividade. Outro aspecto relevante da carcinicultura é o forte envolvimento socioeconômico da atividade que proporciona empregos, produz riquezas e divisas (GRANDI, 2004).

Segundo SOUZA-FILHO et al. (2003), 96\% da produção brasileira de camarão concentram-se no Nordeste e 3\% na região Sul (impulsionada pelo estado de Santa Catarina). Dados do IBAMA mostram que na região Nordeste a produção total proveniente da aquicultura de água doce passou de $32.459 t$ em 2003 para $39.153 t$ em 2004. Já a produção total da aquicultura marinha ficou reduzida em aproximadamente 18\%, passando de $85.852 t$ em 2003 para $70.695 t$ em 2004 (ABCC, 2006).

Os dados do Censo da Carcinicultura Nacional de 2004 (IBAMA, 2005) apontaram a região Nordeste como a maior produtora no período (70.695 $t$ ), embora tenha acumulado perda significativa em relação ao ano de 2003 (85.852 $t$ ) (Tabela 1). Em 2006, apesar da diminuição na produção quando comparada a 2004, o Nordeste foi responsável por $98 \%$ da produção nacional de camarão e permaneceu na liderança (IBAMA, 2008).

De acordo com a Associação Brasileira de Criadores de Camarão (ABCC, 2006), tanto a produção como as exportações entraram em ritmo de queda a partir do ano de 2003. Apesar do decréscimo da produção, os laboratórios de larvicultura e as indústrias de processamento mantiveramse em atividade. O número de fazendas nos 14 estados brasileiros produtores subiu de 905 para 997 e a área cultivada de 14.824 para 16.598 hectares (RABELO e NUNES, 2006). 
TABELA 1 - PRODUÇÃO DA CARCINICULTURA BRASILEIRA EM TONELADAS (2003 A 2008)

\begin{tabular}{|c|c|c|c|c|c|c|}
\hline Estadol Região & $2003^{1}$ & $2004^{2}$ & $2005^{3}$ & $2006^{4}$ & $2007^{5}$ & $2008^{\star^{5}}$ \\
\hline Região Norte & 324 & 242 & 278 & 250 & 200 & 300 \\
\hline Pará & 324 & 242 & 278 & 250 & 200 & 300 \\
\hline Região Nordeste & 85.852 & 70.695 & 59.034 & 63.750 & 63.500 & 67.800 \\
\hline Rio Grande no Norte & 37.473 & 30.807 & 25.063 & 26.400 & 27.000 & 28.000 \\
\hline Ceará & 25.915 & 19.405 & 17.356 & 22.000 & 21.500 & 24.000 \\
\hline Bahia & 8.211 & 7.577 & 5.844 & 6.000 & 6.000 & 6.500 \\
\hline Pemambuco & 5.831 & 4.531 & 3.568 & 3.850 & 3.000 & 3.000 \\
\hline Paraíba & 3.323 & 2.963 & 1.672 & 1.450 & 1.200 & 1.200 \\
\hline Piauí & 3.309 & 2.541 & 2.239 & 1.400 & 1.200 & 1.500 \\
\hline Sergipe & 957 & 2.543 & 2.924 & 2.300 & 3.000 & 3.000 \\
\hline Maranhão & 703 & 226 & 246 & 200 & 300 & 400 \\
\hline Alagoas & 130 & 102 & 122 & 150 & 300 & 200 \\
\hline Região Sudeste & 370 & 370 & 435 & 50 & 300 & 400 \\
\hline Espírito Santo & 370 & 370 & 435 & 50 & 300 & 400 \\
\hline Região Sul & 3644 & 4.597 & $3.386,5$ & 950 & 1.000 & 1.500 \\
\hline Santa Catarina & 3251 & 4.267 & $2.726,5$ & 480 & 580 & 1.000 \\
\hline Paraná & 390 & 310 & 637 & 450 & 400 & 480 \\
\hline Rio Grande do Sul & 3 & 20 & 23 & 20 & 20 & 20 \\
\hline TOTAL & 90190 & 75.904 & $63.133,5$ & 65.000 & 65.000 & 70.000 \\
\hline
\end{tabular}

*Projeção.

Fontes: ${ }^{1}$ IBAMA (2004); ${ }^{2}$ BBAMA (2005); ${ }^{3}$ BAAMA (2007); ${ }^{4}$ IBAMA (2008); ${ }^{5}$ ROCHA (2009).

O principal produto de exportação na área de pescados brasileiros é o camarão, que apresentou crescimento vertiginoso em 2003, não só em termos de quantidade como também em divisas geradas (IBAMA, 2004).

O Brasil exporta camarão para 24 países dos quais 6 (França, Espanha, Japão, Holanda, Portugal e Estados Unidos da América) recebem 96\% das exportações (ABCC, 2007).

A participação do continente Europeu no destino das exportações de camarão do Brasil aumentou de $80 \%$ em 2004 para 93\% em 2006, enquanto que a participação dos Estados Unidos caiu de 16\% para $2 \%$ no mesmo período (ABCC, 2007).

O volume de camarão exportado pelo Brasil em 2006 caiu 25\% em comparação ao ano de 2005. Paraíba, Bahia e o Rio Grande do Norte foram os estados exportadores que tiveram as maiores quedas, ficando o Ceará com a liderança e o Rio Grande do Norte passou de primeiro para o segundo colocado (ABCC, 2007).

\section{COMPONENTES ESTRUTURAIS E CARACTERÍSTICAS QUÍMICAS DO CAMARÃO}

O camarão caracteriza-se por suas longas patas e abdome não dobrado por baixo da carapaça. Menores que as lagostas, os camarões comuns atingem até $20 \mathrm{~cm}$ de comprimento. A maioria das espécies apresenta tamanho reduzido e algumas revelam dimensões microscópicas. São encontrados em mares, nas costas marítimas, nos leitos lamacentos dos riachos, rios e lagoas, bem como nos alagados deixados pelas marés. Constituem importante elemento na cadeia biológica marinha, pois servem de alimento para diversos peixes (CRUSTÁCEO, 2005).

Os camarões apresentam segmentos que se diferenciam em grupos (Figura 1). O cefalotórax anterior é rígido e coberto por exoesqueleto endurecido, que contém quitina e que recobre o dorso e as 
laterais (STORER et al., 1998). O tronco (tórax e abdome) é menos uniforme que o cefalotórax e o número de seus segmentos varia de maneira característica de um grupo para outro. Também há a cauda terminal portadora do ânus na sua base (BARNES, 1990). Muitos dos apêndices no cefalotórax e no abdome relacionam-se com a defesa, a captura de alimento, a locomoção e a reprodução, permitindo melhor exploração do ambiente (CRUSTÁCEO, 2005). A cor vermelha dada pelo cozimento dos camarões resulta da desnaturação da parte proteica do pigmento astaxantina, que é azulada ou verde no seu estado conjugado (VILLE et al., 1988).

\section{FIGURA 1 - ANATOMIA EXTERNA DO CAMARÃO}

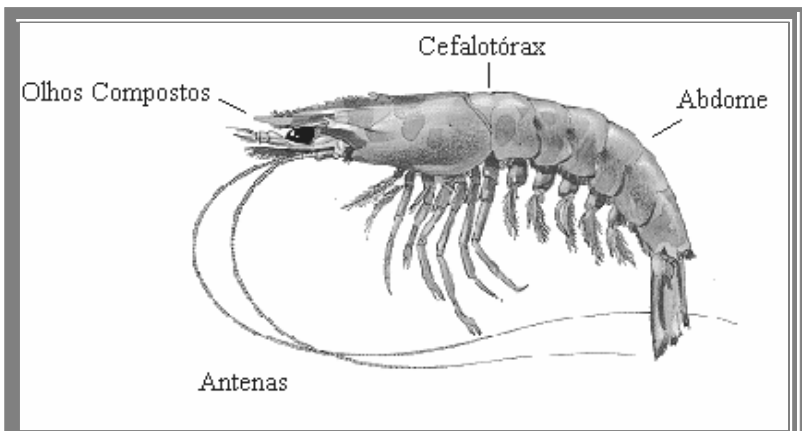

O sistema digestório dos camarões é completo e formado por boca ventral, estômago (dividido em duas câmaras: cardíaca anterior dilatada e pilórica menor atrás), intestino médio curto, intestino tubular delicado, ânus e duas glândulas digestivas grandes (hepatopâncreas) (VILLE et al., 1988; STORER et al., 1998).

A excreção depende de glândulas situadas no cefalotórax e das glândulas verdes ou antenárias, que retiram excretas do sangue e as eliminam por poros na base das antenas (LINHARES e GEWANDSZNAJDER, 1992).

Segundo HEU, KIM e SHAHIDI (2003), a cabeça, a cauda e a casca são geralmente removidas durante o processamento do camarão. Isso representa aproximadamente $50 \%$ do seu peso total, o que favorece a aplicação desses resíduos no processamento de alimentos (SHAHIDI, ARACHCHI e JEON, 1999; JEON, SHAHIDI e KIM, 2000).

VASCONCELOS e SILVEIRA (2004) apontaram a necessidade de novas pesquisas de cunho nutricional para o melhor aproveitamento do cefalotórax e exoesqueleto. Esses constituintes representam $32,38 \%$ e 9,69\%, respectivamente, e quando somados aos apêndices (5,05\%) alcançam $47,12 \%$ do peso total médio do camarão branco (Litopenaeus vannamei). O rendimento da carne representa $52,83 \%$ do peso total, sendo o maior componente estrutural do camarão. Os mesmos autores afirmaram que o processamento mínimo da carne ou a utilização das diversas estruturas do camarão maximizam o retorno financeiro da produção por adicionar valor agregado ao produto final devido, principalmente, à composição nutricional desses componentes.

HEU, KIM e SHAHIDI (2003) analisaram o rendimento dos componentes estruturais de duas espécies de camarão (Pandalus borealis - camarão-rosa e Trachypenaeus curvirostris - camarão manchado). Encontraram contribuição dos resíduos (cabeça, casca e cauda) de aproximadamente $52 \%$ do peso total do camarão de ambas as espécies, ressaltando a importância econômica e industrial do seu aproveitamento.

SILVA et al. (2005) obtiveram rendimento de 55\% em filé de camarão sete-barbas (Xiphopenaeus kroyeri). Relataram a possibilidade do aproveitamento integral do camarão com a utilização dos resíduos (32\% de cabeça e $13 \%$ de casca) na obtenção de farinha ou outros produtos.

Quanto à composição química, HEU, KIM e SHAHIDI (2003) encontraram para as espécies de 
camarão-rosa e manchado, respectivamente, teores de proteína bruta de 13,4\% e 14,9\% (músculo), 9,3\% e 11,6\% (resíduo); lipídios de 0,4\% e 0,3\% (músculo), 0,6\% e 0,7\% (resíduo); cinzas de 1,6\% e 1,5\% (músculo), 8,2\% e 7,0\% (resíduo); e umidade de $84,4 \%$ e $83,1 \%$ (músculo), $79,1 \%$ e $78,5 \%$ (resíduo).

O conteúdo de umidade e cinzas nas espécies de camarão tigre-verde e pintado foi maior no inverno e outono, respectivamente. Com relação aos minerais ( $\mathrm{K}, \mathrm{P}, \mathrm{Na}$ e $\mathrm{Fe}$ ), ambas as espécies apresentaram diferenças sazonais (YANAR e CELIK, 2006).

A composição química dos componentes estruturais do camarão $L$. vannamei revelou valores mais expressivos de proteína na carne $(17,83 \%)$ e no exoesqueleto $(14,94 \%)$, enquanto que o teor de lipídios foi maior no cefalotórax (8,71\%) (VASCONCELOS e SILVEIRA, 2004).

SILVA et al. (2005) verificaram bom valor nutricional para o camarão sete-barbas (Xiphopenaeus kroyeri) que apresentou $75,04 \%$ de umidade, 16,05\% de proteína bruta, 2,96\% de lipídios e 5,94\% de cinzas.

YANAR e CELIK (2006) determinaram o conteúdo de minerais e aminoácidos de duas espécies de camarão (Penaeus semisulcatus - camarão tigre-verde e Metapenaeus monoceros - camarão pintado) durante as quatro estações do ano. Observaram que o conteúdo de proteína bruta variou de $20,44 \%$ a $21,70 \%$ para o camarão tigre-verde e de $21,06 \%$ a 22,46\% para o camarão pintado, obtendo maiores valores durante o verão em ambas as espécies.

A composição total de aminoácidos dos resíduos do camarão manchado e rosa representou $71,1 \%$ e 64,6\%, respectivamente, dos aminoácidos encontrados no músculo (HEU, KIM e SHAHIDI, 2003).

YANAR e CELIK (2006) observaram variação significativa em função da sazonalidade quanto ao total de aminoácidos nas espécies de camarão tigre-verde e pintado. Os maiores valores foram encontrados no verão. Os aminoácidos mais abundantes foram: ácido glutâmico, ácido aspártico, arginina, lisina e leucina, correspondendo a $50 \%$ do total de aminoácidos. A metionina e a histidina foram, respectivamente, o primeiro e segundo aminoácidos limitantes.

Apesar de constituir fonte rica de proteína, o camarão é apontado como alimento com alto conteúdo de colesterol (BRAGAGNOLO e RODRIGUES-AMAYA, 1997).

Durante a determinação dos teores de lipídios totais, colesterol e ácidos graxos em camarãorosa (Penaeus brasiliensis), BRAGAGNOLO e RODRIGUES-AMAYA (1997) encontraram teor médio de $1 \%$ de lipídios. A média de colesterol $(127 \mathrm{mg} / 100 \mathrm{~g}$ ) diferiu da obtida por outros autores, devido diferenças de espécies, estação do ano, tipo de alimentação, tamanho, local de origem e também ao método utilizado. Para o Expert Panel on Food Safety and Nutrition (1991), o músculo do camarão contém menos que $1 \%$ de lipídios totais porque o depósito de gordura é no hepatopâncreas, que fica localizado na região da cabeça.

CAULA, NUNES e MAIA (2004), pesquisando os teores de colesterol e lipídios em pescados, encontraram no camarão 162,0 mg/100 g de colesterol no cefalotórax e 133,9mg/100 g no músculo. Com relação aos lipídios obtiveram 3,8\% na cabeça e 1,3\% na cauda do camarão.

Quanto à composição de ácidos graxos, CHANMUGAN et al. (1983) afirmaram que há predominância de ácidos graxos poliinsaturados ômega seis ( $\omega 6)$ nos camarões de água doce e poliinsaturados ômega três $(\omega 3)$ nos marinhos.

No camarão-rosa, o total de ácidos graxos saturados, monoinsaturados e poliinsaturados foram de 30,2\%, 22,6\% e 45,0\%, respectivamente. Dos ácidos graxos saturados, o palmítico foi o predominante $(14,9 \%)$ e dos monoinsaturados o ácido oleico $(7,9 \%)$ e o palmitoleico $(6,3 \%)$. Já nos poliinsaturados, o ácido eicosapentaenoico (EPA) e o ácido docosahexaenoico (DHA) representaram $32 \%$ do total de ácidos graxos (BRAGAGNOLO e RODRIGUES-AMAYA, 1997).

JOHNSTON et al. (1983) enfatizaram que as variações nos níveis de colesterol e ácidos graxos em camarões podem ser atribuídas à temperatura das águas, estágio de desenvolvimento, nutrição e fotoperíodo, dentre outros fatores.

As carapaças dos crustáceos são as principais fontes naturais de quitina, fibra natural mais 
abundante depois da celulose e precursora da quitosana. A quitina constitui de $15 \%$ a $20 \%$ do peso de carapaças de crustáceos, apresentando grande variedade de usos, principalmente nas indústrias têxtil, alimentícia e de cosméticos (SHAHIDI, ARACHCHI e JEON, 1999).

\section{CARCINICULTURA E MEIO AMBIENTE}

O acelerado desenvolvimento da carcinicultura marinha mundial, nacional e em especial na região Nordeste, coloca em evidência a questão da sustentabilidade ambiental da atividade nos próximos anos e a correta avaliação dos riscos que os ecossistemas brasileiros estão expostos (LUCCHESE e BATALHA, 2003; ORMOND et al., 2004).

Embora a carcinicultura possa causar impactos ao meio ambiente, devido à implementação de vários cultivos com deficiências no seu planejamento e manejo (LUCCHESE e BATALHA, 2003), a criação de camarão em cativeiro tem permitido a redução do extrativismo e da pesca predatória. Também tem transferido mão de obra para o cultivo de organismos aquáticos e repercutido positivamente na preservação de diversos ecossistemas (LENOCH et al., 2003), na geração de empregos diretos e indiretos e na capacidade de estímulo para a fixação do homem na terra (LUCCHESE e BATALHA, 2003).

Segundo QUEIROZ e MOURA (1996), a exploração racional de determinados ecossistemas mediante cultivo que não causem impactos ambientais negativos contribuirá para o desenvolvimento socioeconômico e, principalmente, para o controle e preservação desses ambientes.

A garantia da sustentabilidade da carcinicultura nacional depende do conhecimento e monitoramento dos impactos ambientais da atividade nos ecossistemas brasileiros; do estabelecimento da capacidade de suporte das bacias destinadas à cultura do camarão; e dos investimentos em pesquisas voltadas para o desenvolvimento de tecnologias que neutralizem ou reduzam substancialmente esses impactos (ORMOND et al., 2004).

As indústrias pesqueiras, no Brasil, contribuem para o aumento do problema da contaminação ambiental, visto que a geração de resíduos inicia-se ainda no barco pela captura de espécies de baixo valor comercial e pelo acondicionamento inadequado do pescado a bordo (PESSATTI et al., 2000).

As indústrias de beneficiamento de pescado também geram grandes quantidades de resíduos, devido principalmente à falta de conhecimento sobre o modo de explorá-los como matéria-prima. Aproximadamente $50 \%$ da biomassa de pescado produzida no Brasil é descartada durante o processo de enlatamento, ou em outras linhas de produção como a filetagem (PESSATTI et al., 2000). Além de criar potenciais problemas ambientais representam perdas de matérias-primas e energia, exigindo investimentos significativos em tratamentos para controlar a poluição (TIMOFIECSYK e PAWLOWSKY, 2000).

De acordo com a Norma Brasileira Regulamentadora 10.004 (ABNT, 2004), resíduos sólidos e semissólidos são aqueles que resultam das atividades de origem industrial, doméstica, hospitalar, comercial, agrícola e de serviços de varrição. A classificação de resíduos envolve a identificação do processo que lhes deu origem e para efeito dessa norma são divididos em: Classe I = Perigosos e Classe II - Não Perigosos, os quais podem ser subdivididos em Classe II A - Não inertes e Classe II B - Inertes.

Os resíduos da indústria da pesca podem ser incluídos na Classe I - Perigosos (apresentam propriedades físicas, químicas ou infecto-contagiosas, que oferecem risco à saúde pública e ao meio ambiente) e na Classe II - Não Inertes (com propriedades como a combustibilidade, biodegradabilidade, ou solubilidade em água). Os resíduos da Classe II das indústrias pesqueiras são aqueles com maior potencial para a reciclagem (PESSATTI et al., 2000).

Devido à facilidade de serem transformados em diversos produtos e por apresentarem nutrientes de elevado valor biológico, os resíduos das indústrias de pescado são os mais utilizados. Esses resíduos podem ser destinados para vários tipos de aproveitamento incluindo produtos para consumo 
humano. No entanto, sua maior parte está voltada para a produção de subprodutos como ingredientes de ração animal (STORI, BONILHA e PESSATTI, 2002).

Segundo PESSATTI et al. (2000), os principais produtos de interesse da indústria, elaborados a partir de resíduos de pescado, foram bolinhos, "fishburguer", salsicha, nuggets e kani-kama.

\section{APROVEITAMENTO DOS RESÍDUOS DO BENEFICIAMENTO DO CAMARÃO}

A agregação de valor no beneficiamento final de camarão é outra prioridade da carcinicultura marinha brasileira. O beneficiamento do camarão se inicia com a eliminação das impurezas provenientes dos viveiros, classificação por faixa de tamanho, seguido da embalagem e congelamento. A maioria das exportações brasileiras recebe apenas esse tratamento básico (ORMOND et al., 2004).

Os camarões não vendidos in natura são encaminhados para linhas de produção distintas, sendo a de produção de camarões descabeçados (sem cefalotórax, porém com exoesqueleto) e a de camarões descascados por completo (filé) as mais comuns (PESSATTI et al., 2000). Outras formas de beneficiamento, como a abertura do camarão no sentido longitudinal para colocação em espetinhos, empanamento e pré-cozimento quase não são explorados (ORMOND et al., 2004).

Os resíduos gerados durante o beneficiamento têm sido destinados à fabricação de ração animal ou simplesmente descartados (FREITAS et al., 2002a). A produção de farinha de subprodutos de camarão, reconhecida como excelente fonte de proteína animal, teve aumento significativo devido ao crescimento do cultivo de camarão (FANIMO et al., (2000).

BELLAVER e ZANOTTO (2004) definiram a farinha de resíduo de camarão como partes de camarões não decompostas, desidratadas e moídas secas, cuja umidade não deve exceder a 10\% (situando-se entre 4 e 6\%) com teor de gordura entre 8 e $16 \%$ e acidez de $5 \mathrm{mg}$ de $\mathrm{NaOH} / \mathrm{g}$ de amostra.

CARVALHO et al. (2005) afirmaram que as farinhas obtidas de resíduos de camarão-rosa e pistola podem ser destinadas ao consumo humano, desde que submetidas a processamento que garanta boas condições higiênico-sanitárias ao produto.

BERY et al. (2005) ratificaram o uso da farinha de resíduos dos camarões pistola e rosa para o consumo humano, devido ao seu elevado teor de proteína bruta (35\%) e ao baixo teor de lipídios $(0,6 \%)$.

FREITAS et al. (2002b) encontraram elevado teor de fibra alimentar na farinha da casca do camarão-sete-barbas $(15,38 \%)$ que atribuíram à quitina, normalmente presente nas carapaças dos crustáceos e que não foram digeridas no processo de análise. Os mesmos autores relataram elevado teor de cinzas $(38,29 \%)$ e baixos teores de proteína $(7,46 \%)$ e lipídios $(2,66 \%)$ da farinha quando comparada ao camarão in natura.

FERRAREZZO et al. (2004) desenvolveram "snack" a partir de farinha de cabeça de camarão (P. vannamei) que continha: $2,66 \%$ de lipídios, $14,20 \%$ de proteínas, $3,88 \%$ de carboidratos, 199,46 mg/100 g de sódio, 208,42 mg/100 g de potássio e 1385 mg/100 g de cálcio.

Segundo SHAHIDI e SYNOWIECKI (1991), os lipídios dos resíduos do camarão (Pandalus borealis) são constituídos principalmente de ácidos graxos insaturados.

Visando o aproveitamento integral do camarão-sete-barbas na alimentação humana, FREITAS et al. (2002a) determinaram os teores de lipídios totais, colesterol e a composição em ácidos graxos dos resíduos desidratados do seu beneficiamento. O teor de lipídios foi de 2,66 e o de colesterol de 98,82 mg/100 g, tendo como principais ácidos graxos saturados: palmítico (C16:0) e esteárico (C18:0); monoinsaturados: palmitoleico (C16:1) e oleico (C18:1); poliinsaturados: araquidônico (C20:4), eicosapentaenoico (EPA) e docosahexaenoico (DHA).

O valor nutricional da farinha de resíduo de camarão depende da quantidade de exoesqueleto, composto principalmente de quitina que forma parte do complexo proteico e apresenta baixa digestibilidade (FANIMO et al., 2000). 
No que diz respeito ao aspecto microbiológico, HEU, KIM e SHAHIDI (2003) encontraram contagem total de células viáveis para o resíduo do camarão-rosa e manchado de $2,8 \times 10^{4} \mathrm{UFC} / \mathrm{g}$ e $1,2 \times 10^{4} \mathrm{UFC} / \mathrm{g}$ respectivamente.

MENDES et al. (2002) avaliaram os aspectos microbiológicos do camarão L. vannamei em amostras cruas pré-cozidas com 3 e $4 \%$ de sal e defumadas com e sem casca. Constataram ausência de Salmonella em $25 \mathrm{~g}$ da amostra, Staphylococcus aureus $<10 \mathrm{UFC} / \mathrm{g}$ e coliformes fecais $<3 \mathrm{NMP} / \mathrm{g}$, estando todas as amostras aptas para o consumo.

A viabilidade da produção de subprodutos, a partir dos resíduos do pescado, está diretamente relacionada à qualidade durante as etapas da linha de produção, desde a captura até a comercialização (PESSATTI et al., 2000).

Há dois pontos críticos que devem ser levados em consideração durante a produção e o armazenamento de farinha de pescado: a rancificação e a contaminação por microrganismos. Esses fatores, além de diminuir o tempo de prateleira do produto, podem causar efeitos indesejáveis ao alimento e consequentemente à saúde (STEVANATO, 2006).

\section{CONSIDERAÇÕES FINAIS}

Pode-se afirmar que pesquisas na área de aproveitamento do resíduo gerado pelas indústrias de beneficiamento do camarão são poucas, necessitando mais estudos a fim de desenvolver novos produtos alimentícios que apresentem valor nutricional, aceitabilidade dos consumidores e favoreçam a preservação do meio ambiente e gerem fonte de renda.

\section{ABSTRACT}

\section{SHRIMP WASTE UTILIZATION}

The present literature review had as objective to provide information about the importance of shrimp waste utilization. The following aspects were covered: the evolution of carcinoculture; shrimp's structural components and its chemical characteristics; the relation of carcinoculture with the environment and the utilization of the processing waste. The study attested the great nutritional potential that the processing waste showed, thus making researches necessary, with the objective of making possible its utilization for human alimentation.

KEY-WORDS: CARCINOCULTURE; SHRIMP RESIDUE; SHRIMP.

\section{REFERÊNCIAS}

1 ABCC. Associação Brasileira dos Criadores de Camarão. Exportações e mercado do camarão cultivado do Brasil. Natal, 2007. 53 p. (Boletim mensal).

2 ABCC. Associação Brasileira dos Criadores de Camarão. Valor das exportações de camarão cultivado - 2000/2005. Disponível em: <http: www.abccam.com.br> Acesso em: 08 de março de 2006.

3 ABNT. Associação Brasileira de Normas Técnicas. NBR 1004: resíduos sólidos - classificação. Rio de Janeiro, 2004.

4 BARNES, R.D. Os crustáceos. In: . Zoologia dos invertebrados. 4. ed. São Paulo: Ed. Roca, 1990. p. 713867.

5 BELLAVER, C.; ZANOTTO, D. Parâmetros de qualidade em gorduras e subprodutos protéicos de origem animal. Palestra apresentada na Conferência APINCO, Santos, SP, 2004. Disponível em: <http://www.cnpsa. embrapa. br/ sgc/sgc_arquivos/palestras_k9r8d4m.pdf> Acesso em: 14 de novembro de 2005

6 BELTRAME, E. Seleção de sítios e planejamento da atividade de cultivo de camarões marinhos com base em geotecnologias. Florianópolis, 2003. 212 f. Tese (Doutorado em Geografia) - Universidade Federal de Santa Catarina. 
7 BERY, C.C.S.; CARVALHO, M.S.; SOUZA, D.C.L.; CASTRO, A.A. Estudo físico-químico da farinha dos resíduos de camarões rosa e pistola para o consumo humano. In: SIMPÓSIO LATINO AMERICANO DE CIÊNCIAS DE ALIMENTOS, 6. Ciências de Alimentos: abrindo caminhos para o desenvolvimento científico, tecnológico e industrial, Campinas, 2005. Anais... Campinas: SLACA, 2005. CD Room.

8 BRAGAGNOLO, N.; RODRIGUES-AMAYA, D. Otimização da determinação de colesterol por CLAE e teores de colesterol, lipídios totais e ácidos graxos em camarão rosa (Penaeus brasiliensis). Ciênc. Tecnol. Aliment., Campinas, v.17, n.3, p.275-280, 1997

9 CARCINICULTURA BRASILEIRA: o censo de 2003. Panorama da Aqüicultura. v.14, n.82, p.21-25, 2004.

10 CARCINICULTURA. Disponível em <http://pt.wipedia.org/wiki/carcinocultura. Acesso em: 25 outubro de 2005.

11 CARVALHO, E.A. Efeito da frequência de arraçoamento sobre o desempenho zootécnico do camarão branco (Litopenaeus vannamei) cultivado em cercados sob condições intensivas. Fortaleza, 2005. 43 p. Dissertação (Mestrado em Ciências Marinhas Tropicais), Instituto de Ciências do Mar, Universidade Federal do Ceará.

12 CARVALHO, M.S.; BERY, C.C.S.; SOUZA, D.C.L.; CASTRO, A.A. Estudo microbiológico da farinha dos resíduos de camarões rosa e pistola para o consumo humano. In: SIMPÓSIO LATINO AMERICANO DE CIÊNCIAS DE ALIMENTOS, 6., Ciências de Alimentos: abrindo caminhos para o desenvolvimento científico, tecnológico e industrial, Campinas, 2005. Anais... Campinas: SLACA, 2005. CD Room.

13 CASTRO, A.A.; CAVALCANTI-MATA, M.E.R.M.; DUARTE, M.E.M. Avaliação do sabor de filés de camarão (Litopenaeus vannamei) submetidos a diferentes condições de congelamento e armazenamento. In: CONGRESSO BRASILEIRO DE CIÊNCIAS E TECNOLOGIA DE ALIMENTOS, 21., 2004, Recife. Anais... Recife: SBCTA, 2004. CD Room.

14 CAULA, F.C.B.; NUNES, M.L.; MAIA, E.L. Determinação de colesterol em pescado de importância econômica no Estado do Ceará. In: CONGRESSO BRASILEIRO DE CIÊNCIAS E TECNOLOGIA DE ALIMENTOS, 19., 2004, Recife. Anais... Recife: SBCTA, 2004. CD Room.

15 ChANMUGAN, P.; DONOVAN, J.; WHEELER, C.J.; HWANG, D.H. Differences in the lipid composition of fresh water prawn (Macrobrachium rosenbergii) and marine shrimp. J. Food Sci., v.48, p.1440-1441, 1983.

16 COELHO, M.A.S. Análise de custo/volume/lucro e investimento em carcinicultura de pequeno porte. Custo e @gronegócio on line, v.1, n.1, jan./jun. 2005. Disponível em: <http://www.custoeagronegocioonline.com.br> Acesso em: 15 jun. 2006.

17 CRUSTÁCEO. Disponível em: <http://pt.wikipedia.org/wiki/Crust\%C3\%A1ceo> Acesso em: 1 nov. 2005.

18 EXPERT PANEL ON FOOD SAFETY AND NUTRITION. Foods from aquaculture. Food Tec., v. 9, p. 87-93, 1991.

19 FAÇANHA, S.C.; PINHEIRO, S.M.X.; ABREU, V.L.B. de. Informativo: Litopenaeus vannamei, 2001. Fortaleza: Ministério da Integração Nacional. Departamento Nacional de Obras Contra as Secas/DNOCS. Laboratório de Larvicultura de Camarão. Disponível em: <www.acaq.org.br/arquivos/inf_bas_camarao_vannamei.PDF > Acesso em: 5 dez. 2005.

20 FANIMO, A.O.; ODUGUWA, O.O.; ONIFADE, A.O.; OLUTUNDE, T.O. Protein quality of shrimp-waste meal. Bioresource Technology, v. 72, p.185-188, 2000.

21 FERRAREZZO, E.M.; ROCHA, W.S.; BASTOS, L.C.; ROCHA, A.S.; SILVA, C.M.R.; NORI, M.A. Estudos preliminares para o desenvolvimento de "snack" a partir de farinha de cabeça de camarão. In: CONGRESSO BRASILEIRO DE CIÊNCIA E TECNOLOGIA DE ALIMENTOS, 19., 2004, Recife. Anais... Recife: SBCTA, 2004. CD Room.

22 FREIRE, R.S.; PELEGRINI, R.; KUBOTA, L.T.; DURÁN, N. Novas tendências para o tratamento de resíduos industriais contendo espécies organocloradas. Quim. Nova, v.23, n. 4, p. 504-511, 2000.

23 FREITAS, A.S.; BORGES, J.T. da S.; COSTA, R.K.; CORNEJO, F.E.P.; WILBERG, V. C. Teores de lipídios totais, ácidos graxos e colesterol em resíduos desidratados de camarão-sete-barbas (Xiphopenaeus kroyeri, HELLER 1862) capturado no estado do Rio de Janeiro. B. do CEPPA, v. 20, n.2, p.355-362, jul./dez. 2002a.

24 FREITAS, A.S.; LOPES, A.B.; STEPHAN, M.P.; CORNEJO, F.E.P.; FURTADO, A.A.L. Composição química e protéicomolecular da farinha de resíduos de camarão-sete-barbas (Xinhopenaeus kroyeri). B. do CEPPA, v.20, n.1, p.111120, jan./jun. 2002b.

25 GRANDI, E.M.V. Cultivo do camarão em Santa Catarina: panorama geral, reprodução e larvicultura. Florianópolis: BRDE, 2004.101 p. Disponível em: <http://www.brde.com.br/estudos_e_pub/Cultivo\%20do\%20 Camar\% C3\%A30\%20em\%20Santa\%20Catarina.pdf>. Acesso em: 25 out. 2006.

26 HEU, M. S.; KIM, J.S.; SHAHIDI, F. Components and nutritional quality of shrimp processing by-products. Food Chemistry, v. 82, p. 235-242, 2003. 
27 IBAMA. Instituto Brasileiro do Meio Ambiente e dos Recursos Naturais Renováveis. Estatístico de pesca 2003 Brasil: grandes regiões e unidades da federação. Brasilía, 2004. 98 p.

28 IBAMA. Instituto Brasileiro do Meio Ambiente e dos Recursos Naturais Renováveis. Estatístico de Pesca 2004 Brasil: grandes regiões e unidades da federação. Brasília, 2005. 98 p.

29 IBAMA. Instituto Brasileiro do Meio Ambiente e dos Recursos Naturais Renováveis. Estatístico de pesca 2005 Brasil: grandes regiões e unidades da federação. Brasília, 2007. 108 p.

30 IBAMA. Instituto Brasileiro do Meio Ambiente e dos Recursos Naturais Renováveis. Estatístico de pesca 2006 Brasil: grandes regiões e unidades da federação. Brasília: IBAMA, 2008. 174 p.

31 JEON, Y.J.; SHAHIDI, F.; KIM, S.K. Preparation of chitin and chitosan oligomers and their application in physiological functional foods. Food Reviews International, v.16, n. 2, p.159-176, 2000.

32 JOHNSTON, J.J.; GHANBARI, H.A.; WHEELER, W.B.; KIRK, J.R. Characterization of shrimp lipids. J. Food Sci., v. 48, n.1, p. 33-35. 1983.

33 LENOCH, R.; LEHMANN, M.; GOMES, R.O. de M.; ESPINDOLA, J.C.; BALDISSERA, G.C. Curso técnico em aquicultura. Colégio Agrícola de Araquari. Araquari, Santa Catarina, 2003. Disponível em: < http:// www.cascgo.ufsc.br/ aquicultura.doc > Acesso: 5 set. 2005 .

34 LINHARES, S.; GEWANDSZNAJDER, F. Artrópodos. In: Biologia hoje: seres vivos. São Paulo: Ed. Moderna, 1992. Cap. 15.

35 LUCCHESE, T.; BATALHA, M.O. Produção de camarão marinho no estado de São Paulo: um estudo de viabilidade utilizando indicadores de competitividade da cadeia produtiva. In: CONGRESSO INTERNACIONAL DE ECONOMIA E GESTÃO DE REDES AGROALIMENTARES, 4., Ribeirão Preto, 2003. Faculdade de Economia, Administração e Contabilidade de Ribeirão Preto/USP. Disponível em: <www.pensaconference.org/arquivos_2003/082.pdf> Acesso em: 15 jun. 2006.

36 MENDES, E.S.; MENDES, P. de P.; COELHO, M.I. de S.; SOUZA, J.C.R.; CRUZ, M.C.S.; ASSIS, A.S. de; ALVES, A.B. Aspectos microbiológicos do camarão Litopenaeus vannamei defumado e sua vida-de-prateleira. Higiene Alimentar, v.16, n. 99, p. $75-80,2002$.

37 NANNI, S. Criação do camarão vannamei no litoral paulista. Cienc. Cult., v.56, n.3, p.11-11, jul./set. 2004.

38 NUNES, A.J.P. O cultivo de camarões marinhos no Nordeste do Brasil. Panorama da Aquicultura, v.11, n. 65, p. 26$33,2001$.

39 ORMOND, J.G.P.; MELLO, G.A.T. de; FERREIRA, P.R.P.; LIMA, C.A. de O. A carcinicultura brasileira. BNDES Setorial, n.19, p. 91-118, 2004.

40 PESSATTI, M.L.; PEREIRA, K.C.; STORI, F.T.; BUSCHI, F.L.F. Aproveitamento dos subprodutos do pescado. Meta 11. Relatório final de ações prioritárias ao desenvolvimento da pesca e aquicultura no Sul do Brasil. Convênio Ministério da Agricultura, Pecuária e Abastecimento (MAPA), Universidade do Vale do Itajaí, MA/SARC, n.003/2000. Disponível em: <http://scholar.google.com/scholar?hl=en\&lr=\&q=cache:rbodV9EYI84J:www.gep.cttmar.univali.br/ download/pdf/Docpescado8.pdf+residuos+pescado>. Acesso em: 3 set. 2005.

41 QUEIROZ, J.F.; MOURA, E.V. Aquacultura e recursos pesqueiros: alternativa para o desenvolvimento sócio-econômico do Rio Grande do Norte. Cadernos de Ciências e Tecnologia, Brasília, v.13, n. 2, p.195-224, 1996.

42 RABELO, D.; NUNES, T. Carcinicultura no Ceará: oportunidades e desafios. Fortaleza: Instituto Agropecuário do Ceará, 2006. 24 p.

43 ROCHA, Diego. Produção ABCC. [mensagem pessoal]. Mensagem enviada por abccam@terra.com.br em: 19 ago. 2009.

44 SCHOBER, J. Pesquisa impulsiona produção de camarão em viveiros e mercado de trabalho regional. Cienc. Cult., v.54, n.1, p.10-11, jun./set., 2002.

45 SHAHIDI, F.; ARACHCHI, J.K.V.; JEON, Y.J. Food application of chitin and chitosans. Trends in Food Science and Technology, v. 10, p. 37-51, 1999.

46 SHAHIDI, F.; SYNOWIECKI, J. Isolation and characterization of nutrients and value - added products from snow crab (Chinoecetes opilio) and shrimp (Pandalus norealis) processing discards. J. Agric. Food. Chem., v. 39, p.15271532, 1991.

47 SILVA, J.V.; GOMES, C.E.F.; SALES, P.V.G.; MUJICA, P.Y.C. Caracterização físico-química e avaliação do rendimento do camarão (Xithopenaeus kroyeri). In: SIMPÓSIO LATINO AMERICANO DE CIÊNCIAS DE ALIMENTOS, $6 .$, Campinas, 2005. Campinas. Anais... Campinas: SLACA, 2005. CD Room.

48 SILVA, Maria R. da. Povos de terra e água: a comunidade pesqueira do canto do mangue, Canguaretama (RN) Brasil. São Paulo, 2004. 142 p. Dissertação (Mestrado em Ecologia e Agroecossistemas), Escola Superior de Agricultura "Luiz de Queiroz", Universidade de São Paulo. 
49 SOUZA FILHO, J.; COSTA, S.W. da; TUTIDA, L.M.; FRIGO, Tiago B.; HERZOG, D. Custo de produção do camarão marinho. Ed. rev. Florianópolis: Instituto Cepa/SC/Epagri, 2003. 24 p. (Cadernos de Indicadores Agrícolas, 1)

50 STEVANATO, F. B. Aproveitamento de cabeças de tilápias de cativeiro na forma de farinha como alimento para Merenda Escolar. Maringá, 2006. 69 p. Dissertação (Mestrado em Química), Departamento de Química do Centro de Ciências Exatas da Universidade Estadual de Maringá.

51 STORER, Tracy I. et al. Filo Artropoda: aspectos gerais, quelicerados e grupos menores. In: 6. ed. São Paulo: Companhia Editora Nacional, 1998. p. 463-467.

52 STORI, F.T.; BONILHA, L.E.C.; PESSATTI, M. L. Proposta de aproveitamento dos resíduos das indústrias de beneficiamento de pescado de Santa Catarina com base num sistema gerencial de bolsas de resíduos. In: INSTITUTO ETHOS. Responsabilidade social das empresas: uma contribuição das universidades. Peirópolis: Editora Fundação Peirópolis, 2002, p. 373-406.

53 TIMOFIECSYK, F. do R.; PAWLOWSKY, U. Minimização de resíduos na indústria de alimentos: revisão. B. do CEPPA, Curitiba, v.18, n. 2, p.221-236, jul/dez.2000.

54 VASCONCELOS, M.M.M.; SILVEIRA, V.M.M.A. Rendimento e composição química dos componentes estruturais do camarão branco, Litopenaeus vannamei, cultivado no município de Acaraú/CE. In: CONGRESSO BRASILEIRO DE CIÊNCIAS E TECNOLOGIA DE ALIMENTOS; 19., 2004, Recife. Anais... Recife: SBCTA, 2004. CD Room.

55 VILLE, C.A. et al. A diversidade dos animais - artrópodos. In: Zoologia geral. 6.ed. Rio de Janeiro: Editora Guanabara, 1988. p. 469-478.

56 VILLEN, R.A. Tratamento biológico de efluentes. In: LIMA, U. de A.; AQUARONE, E.; BORZANE, W.; SCHMIDELL, W. Biotecnologia industrial: processos fermentativos e enzimáticos. São Paulo: Edgard Blücher, 2001. v. 3.

57 YANAR, Y.; CELIK, M. Seasonal amino acid profiles and mineral contents of green tiger shrimp (Penaeus semisulcatus De Haan, 1844) and speckled shrimp (Metapenaeus monoceras Fabricus, 1789) from the Eastern Mediterranean. Food Chemistry, v. 94, p. 33-36, 2006. 